\section{VIRTUAL LABORATORY FOR STUDY OF CONSTRUCTION OF MACHINE TOOLS}

JIRI KROUPA, ZDENEK TUMA, JIRI KOVAR, VLADISLAV SINGULE

Brno University of Technology, Faculty of Mechanical Engineering, Brno, Czech Republic

DOI : 10.17973/MMSJ.2018_11_2017100

e-mail : kroupa@fme.vutbr.cz

Virtual reality is quickly evolving technology which is starting to push not only in entertainment but also in other disciplines like an automotive, machine or aircraft industry. Due to ever higher teaching demands of these problematics virtual reality is one of the ways how to increase teaching efficiency. This paper aims to create a virtual laboratory with an interactive model of a machine tool. Head-mounted display and controllers from Oculus were used for the visualization and interaction with the machine tool. The interactivity of model lies in the opportunity of assembling and disassembling basic parts of the machine tool to elementary construction parts. This enables to the interested person better and faster understanding of construction problematics of machine tools which contribute to the improvement of the teaching effectiveness.

KEYWORDS

virtual laboratory, virtual reality, machine tools, visualization, education

\section{INTRODUCTION}

In the last decades, we have been increasingly confronted with the complexity of new technologies. [De Vries 2005]. This can cause increase of required time for understanding specific problematics and thereby complicate the study for an interested person for given topics. On the other hand, with increasing complexity of new technologies, the quality of education is increased as well by using new teaching trends. Informative-communication technologies (ICTS) have an irreplaceable role in an information society. Therefore, it is natural that this part of our life has started to use in education for example in form of electronic courses [Striezovska 2016]. These electronic courses do not have to contain only static materials. They could contain interactive elements like a numeric simulator of the cardiovascular system which is able to reproduce physiological and pathophysiological conditions of patients affected by cardiovascular disease [De Lazzari 2014]. The using of these electronic courses in the field of education have a positive effect on the efficiency of teaching [Ruiz J. 2006].

This paper is divided into the two parts. The first part describes general use of virtual reality (VR) in the field of machine tools and usage in educational purposes. The second part describes development and results of the designed virtual laboratory.

\section{VIRTUAL REALITY IN MACHINE INDUSTRY}

VR is used for different purposes in machine tools area for a long time. It helps reduce cost and time during the design phase of new machine tools by using virtual prototypes. These prototypes are used for validating functionality of new designs in virtual environment by Finite-Element-Analysis or MultiBody-Simulation [Altintas 2005].
During the planning production phase, the VR can be used as a tool for quick prediction of collision between machine tool and workpiece [Tuma 2014]. Another implementation of VR within the planning production phase is realistic machine tool simulation. During the simulation, the machine tool control unit is connected with the virtual model of milling machine and the tool deflection and material removal are simulated [Neugebauer 2012].

From the perspective of maintenance, VR can be used for visualizing energies flows in the machine tools. Energy consumption becomes more and more important factor in electricity costs and also in rising environmental awareness. Visualization by VR enables an easier orientation and control of their energy consumption [Augste 2014, Pelliccia 2016].

\section{VIRTUAL REALITY FOR EDUCATION PURPOSES}

Due to cost of procurement and maintenance VR was beyond the reach of schools. Nowadays, the rapid increase of performance of computers leads to the deployment VR in education [Merchant 2014]. It has a big potential for an improvement of effectiveness in education. This potential lies in attractivity of this technology for student community and in immersion to the virtual environment. Immersion could be defined as a state in which a participant becomes attracted and involved in a virtual space and his mind is separated from the physical space he is being active in [Muhanna 2015]. The degree of immersion is important factor which has big influence in learning effectivity. During the experiment which was focused on the comparation of two types of VR it was discovered following: the group using a Full-Immersive VR (Head mounted display) evinced significantly higher gain than group using a Semi-Immersive VR (computer screen). In both cases was proved that VR has an impact for an effectiveness of learning [Gutierrez 2007]. Therefore, two major ways were found to use VR within the education.

The first way is to use it as visualization. Nanotechnology is one of the discipline which can be used as an example. It is not a trivial discipline and it is based on the understanding of the basic science about electrons, atoms and molecules. None of these microscopic objects are not visible in real life, therefore it can be difficult to imagine them and their behaviour. By visualization of these particles and their behaviour in virtual environment students gain deeper understanding of this problematic [Xie 2012]. The other disciplines where visualizations which can be used in engineering industry, medicine or civil engineering.

The second way of using VR is simulation. From the education point of view, simulation finds application mostly in training activities which are expensive, or their training is dangerous in the real environment. Typical disciplines where VR is used for simulating are aviation and medicine. The Semi-Immersive VR is used for a long time simulations especially for training pilots, for the reason that they can practice dangerous situations like a recover from fully developed stall [Schroeder 2014]. In medicine VR is used especially for practicing surgical intervention. It could be useful in preparing for real-life surgeries [Kirkman 2014]. Experiment during which efficiency of cerebral aneurysm slipping simulator with real-time haptic feedback was evaluated. It was discovered that simulator is useful for preoperative surgical rehearsal and neurosurgical training for two thirds of the neurosurgical residents. For one third of the residents this technology in its current form provided very realistic haptic feedback for aneurysm surgery [Alaraj 2015]. 
The application of visualization and simulation can be found in virtual laboratories. It could be defined as a web application or software for interactive learning which is based on simulation or real phenomena, allowing to students to explore a topic by comparing and contrasting different scenarios [Kuleshov 2008]. They find use of it in a lot of disciplines: like a science (physic, biology, chemistry), process technology, engineering or robotics. The advantages of virtual laboratories are: costefficient way how to get a high-quality laboratory, flexibility, multiple access and damage resistance. On the other hand there are some disadvantages like a request imposed to computer resources, lack of seriousness, responsibility and carefulness from students and finally, a fact that the final stage in training usually requires real equipment [Potkonjak 2016].

\section{VIRTUAL LABORATORY DEVELOPMENT}

With the increasing requirements on the machine tools capabilities, the construction complexity of them is also increased [Shagluf 2014]. This can increase required time to learn and understand this problematic. Due to this reason virtual laboratory was developed. The following section summarize the process used to develop the virtual laboratory and the implementation in VR.

\subsection{Objectives}

The main idea lies in creating a tool which will help students to better understand machine tools construction. Before the implementation of virtual laboratory, several objectives which should be fulfilled were specified. These objectives are:

\section{- $\quad$ VR support}

- Freedom movement in the laboratory

- Visualization of basic parts of machine tool

- Opportunity to rotate specific parts of machine tool

- Assembly/disassembly animation for each basic part

On the impact base of the teaching efficiency between Fullimmersive and Semi-Immersive VR [Gutiérrez 2007] it was decided to use Full-Immersive VR for designed virtual laboratory. The virtual laboratory aims on the visualization of basic construction parts of machine tool and interaction with them. These basic construction parts are frame, table, crossbeam, ram and automatic tool changer (ATC). Students have the possibility to study all these parts in detail. For this purpose, basic parts can be disassembled to the elementary construction parts. Free movement in the laboratory, together with possibility of rotation with chosen parts are important features which enables to study parts of machine tool with unfavorable accessibility.

\subsection{Machine tool model}

Model of multifunctional machining centre is shown in Figure 1. which was used for our virtual laboratory. This centre is designed for machining rotating and prismatic parts by three basic technologies of machining. These technologies are milling, turning and drilling. The kinematic structure of centre is upper gantry with rotary table with 4 axes. By using NC milling heads the machine becomes a fully-fledged 5 axes machine. It also contains ATC which is placed out of the working area. The individual tools are placed in the disc magazines which contains 19 tools.
The original model of machine tool contains an enormous quantity of polygons. Due to the high requirements of VR on hardware, the parts which are not relevant, like a bolts, nuts and non-visible parts are removed. This reduce quantity of polygons and hardware demands of the scene.

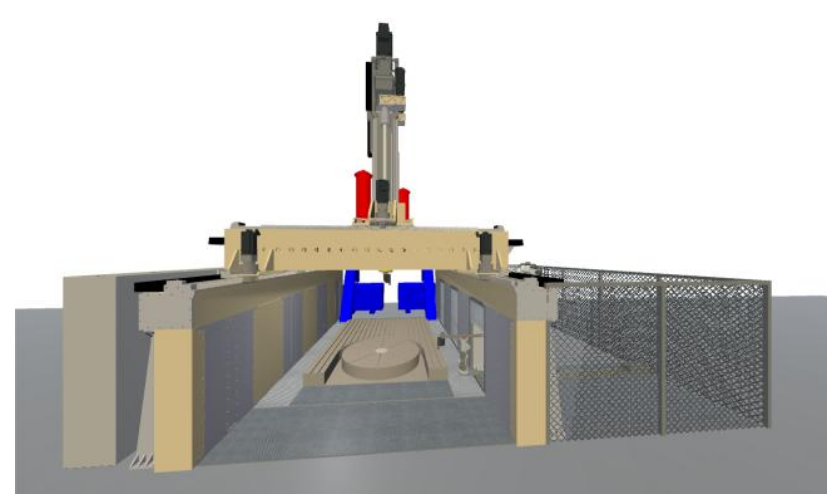

Figure 1. Multifunctional machining centre used for virtual laboratory

\subsection{Development environment and VR hardware}

The choice of development environment depends on the choice of the platform for virtual reality. Therefore, the first step is selection of virtual reality technology. The market has several types of VR devices. There are CAVE and PowerWall solutions or HMDs like Oculus Rift or HTC Vive. For the purposes of virtual laboratory is chosen HMD Oculus Rift with controllers Oculus Touch. The reason for this choice is to fulfil requirements for the project and its low price. Oculus Rift support developing in game engines like a Unity3d, Unreal Engine or developing applications by using Oculus SDK. For the implementation was chosen game engine Unity3D. Reasons are:

- Support of several types of VR devices like HMDs from Oculus, HTC, CAVE and PowerWall

- Support of C\# scripting

- Opportunity to use free license

This virtual laboratory can be reworked to another virtual platform by using the minor changes if it's necessary because the Unity3D supports other types of VR.

\section{RESULTS AND DISCUSION}

Unity3D engine is powerful tool for developing applications which enables importing 2D and $3 \mathrm{D}$ scenes and also provides animation tool, physic engine etc. However, program algorithm, user interface and animation of parts had to be developed separately. Teaching support of construction of machine tools is the major purpose but the application is designed as a universal software tool for decomposition of any assembly in VR.

The interaction system of designed application is based on the event-driven programming. Main program script is responsible for handling the events by triggering appropriate methods when one of those events are detected.

The machine tool model consists of five basic parts, specifically frame, table, automatic tool changer, cross-beam and ram. A laser pointer was implemented to the virtual environment as a tool for selection of these basic parts. If the laser pointer is aimed to one of these parts, event is invoked. Two kinds of 
events could be invoked by interaction between laser pointer beam and machine tool part. First event is initiated by entering collision and second one by exiting collision. The focused part is highlighted when OnEnterCollision event is invoked. When the part is highlighted, it could by selected by pressing the corresponding button on the controller. After the selection the remaining parts hide and only the selected part is visible on the scene. The process of selection and interaction with machine tool part is shown in Figure 2. It is possible to disassemble or assemble the selected part. This action is accessible through the VR menu which is displayed by pressing the menu button on the controller.
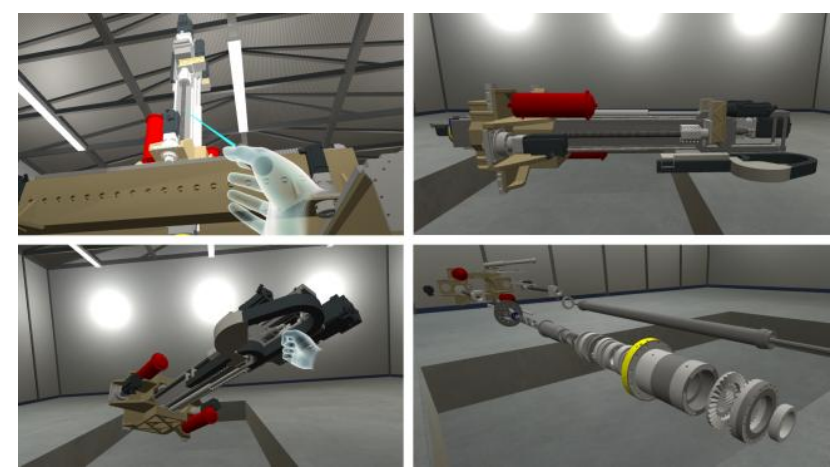

Figure 2. Interaction process with machine tool ram, a) part selection by using laser pointer, b) part is isolated and moved to more convenient position after part selection, c) at this point user can rotate with selected part, d) disassembling

One of three items from VR menu can be selected by touching it. These items are disassembly/assembly, reset rotation and close button. Button highlighting is implemented for easier orientation of hand position while focusing on the button. The VR menu is shown in Figure 3.
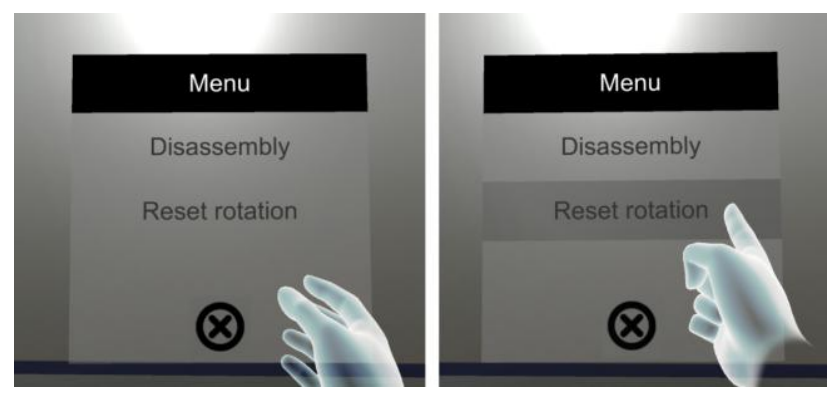

Figure 3. Demonstration of user interface. VR menu is shown in the left picture. The menu is controlled by touch gesture which is shown in the right image

The selected part can be rotated by using 'grab' gesture. Default part rotation can be set by pressing 'reset rotation' button in VR menu. In order to move around the laboratory, a teleport function was created. Teleportation is controlled by thumbstick. If the thumbstick is not in the central position, teleportation mark is shown on the place where the controller is pointing. Direction of the thumbstick tilt represents new camera orientation after the teleportation. The teleportation is executed when the thumbstick is released. The teleportation system is shown in Figure 4.

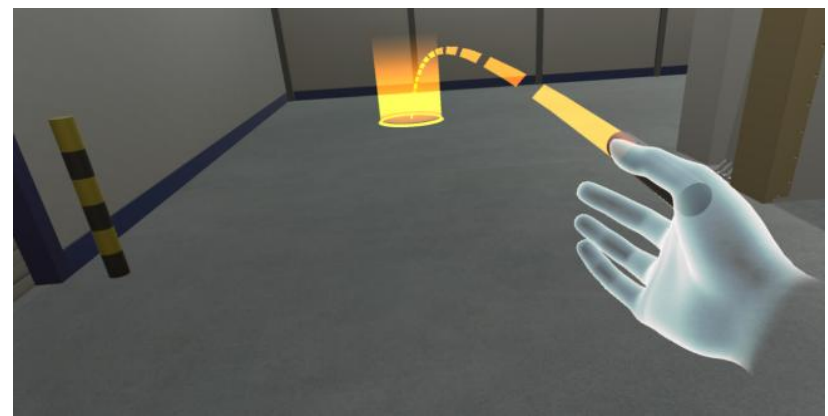

Figure 4. Example of teleportation system used for free movement in the virtual environment

\section{CONCLUSIONS}

The virtual laboratory for construction learning of machine tools is developed and described. The lab is based on the Unity3D game engine which allows to create interactive 3D laboratory with support of VR. HMD Oculus Rift is used for the visualization of virtual laboratory and interactions are possible by using Oculus Touch controllers. The developed laboratory contains fully interactive model of multifunctional machining centre, which can be disassembled/assembled by the user. It provides a possibility to rotate selected parts and also free movement around the laboratory. This solution enables decomposition of any assembly in VR. Except in educational purposes the solution can be used for verification of construction design by designers. The following aim is to deploy a virtual laboratory in teaching and evaluate benefits from its deploying. In the future work the VR application will be connected to database system containing information about individual parts of assembly. With this solution it will be able to show information about parts in virtual reality. Thanks to this application it will be possible to use it for checking of diagnostic data from machine tools as well.

\section{ACKNOWLEDGMENTS}

This work has been supported by Brno University of Technology, Faculty of Mechanical Engineering, Czech Republic (Grant No. FV 17-28).

\section{REFERENCES}

[Alaraj 2015] Alaraj, A. et al. Virtual reality cerebral aneurysm Clipping simulation with real-time haptic feedback.

Neurosurgery, 2015, Vol.11, No.2, pp 52-58, ISSN 1524-4040. [Altintas 2005] Altintas, Y. et al. Virtual Machine Tool. CIRP Annals - Manufacturing Technology, 2005, Vol.54, No.2, pp 115-138, ISSN 0007-8506.

[Augste 2014] Augste, J. et al. Monitoring of Energy Flows in the Production Machines. 10th International Conference on Mechatronics 2013, Brno, October, 2013, pp 1-7, ISBN 978-3 319-02294-9.

[De Lazzari 2014] De Lazzari, C. et al. Interactive simulator for e-Learning environments: a teaching software for health care professionals. Biomedical Engineering Online, 2014, Vol.13, No.1, pp 172, ISSN 1475-925X.

[De Vries 2005] De Vries, M. J. Analyzing the Complexity of Nanotechnology. Techne: Research in Philosophy and Technology, 2005, Vol.8, No.3, pp 62-75, ISSN 1091-8264. [Gutierrez 2007] Gutierrez, F. et al. THE IMPACT OF THE DEGREE OF IMMERSION UPON LEARNING PERFORMANCE IN 
VIRTUAL REALITY SIMULATIONS FOR MEDICAL EDUCATION. Journal of Investigative Medicine, 2007, Vol.55, No.1, pp S91, ISSN 1081-5589.

[Kirkman 2014] Kirkman, M. A. et al. The use of simulation in neurosurgical education and training. Journal of Neurosurgery, 2014, Vol.121, No.2, pp 228-246, ISSN 0022-3085.

[Kuleshov 2008] Kuleshov, G. Web Enhanced vs. Traditional Approach for a Science Course. Handbook of Research on Digital Information Technologies, Denmark: IGI Global, 2008, pp 103-116, ISBN 978-1-599-04970-0.

[Merchant 2014] Merchant, Z. et al. Effectiveness of virtual reality-based instruction on students' learning outcomes in $\mathrm{K}$ 12 and higher education: A meta-analysis. Computers and Education, 2014, Vol.70, pp 29-40, ISSN 0360-1315.

[Muhanna 2015] Muhanna, M. A. Virtual reality and the CAVE: Taxonomy, interaction challenges and research directions. Journal of King Saud University - Computer and Information Sciences, 2015, Vol.27, No.3, pp 344-361, ISSN 2213-1248. [Neugebauer 2012] Neugebauer, R. et al. Realistic machine simulation with virtual reality. Procedia CIRP, 2012, Vol.3, No.1, pp 103-108, ISSN 2212-8271.

[Pelliccia 2016] Pelliccia, L. et al. Energy Visualization Techniques for Machine Tools in Virtual Reality. Procedia CIRP, 2016, Vol.41, pp 329-333, ISSN 2212-8271.

[Potkonjak 2016] Potkonjak, V. et al. Virtual laboratories for education in science, technology, and engineering: A review. Computers and Education, 2016, Vol.95, pp 309-327, ISSN 0360-1315.

[Ruiz J. 2006] Ruiz J., G. et al. The Impact of E- Learning in Medical Education. Academic Medicine, 2006, Vol.81, No.3, pp 207-212, ISSN 1040-2446.
[Schroeder 2014] Schroeder, J. A. et al. An Evaluation of Several Stall Models for Commercial Transport Training. AIAA Modeling and Simulation Technologies Conference 2014, Atlanta, June, 2014, pp 17, ISBN 978-1-624-10297-4.

[Shagluf 2014] Shagluf, A. et al. Maintenance Strategies to Reduce Downtime Due to Machine Positional Errors Maintenance Strategies to Reduce Downtime Due to Machine Positional Errors. Maintenance Performance Measurement and Management, Coimbra, September, 2014, pp 111-118, ISBN 978-972-8954-42-0.

[Striezovska 2016] Striezovska, L. The use of electronic course in practice. ICETA 2015 - 13th IEEE International Conference on Emerging eLearning Technologies and Applications, Proceedings, Slovakia, November, 2015, pp 1-6, ISBN 978-1 467-38534-3.

[Tuma 2014] Tuma, Z. et al. The Process Simulation Using by Virtual Reality. Procedia Engineering, 2014, Vol.69, pp 1015 1020, ISSN 1877-7058.

[Xie 2012] Xie, C. and Lee, H. A visual approach to

nanotechnology education. International Journal of Engineering Education, 2012, Vol.28, No.5, pp 1-17, ISSN 0949-149X.

\section{CONTACT:}

Ing. Jiri Kroupa

Brno University of Technology

Faculty of Mechanical Engineering

Technicka 2896/2, Brno, 616 69, Czech Republic

Tel.: +420 541142291

e-mail: kroupa@fme.vutbr.cz 